\title{
The Application of RBF Neural Networks for the Assessment of the Water Flow Rate in the Pipework
}

\author{
Andrzej Czapczuk ${ }^{1}$ and Jacek Dawidowicz ${ }^{2, *}$ \\ ${ }^{1}$ F.B.I. TASBUD S.A. Science and Research Division, ul. Balaton 20, 01-981 Warsaw, Poland \\ ${ }^{2}$ Bialystok University of Technology, ul. Wiejska 45A, 15-351, Bialystok, Poland \\ ${ }^{*}$ Corresponding author
}

\begin{abstract}
The water distribution system is a spatially large and complex system. Its proper functioning is determined by having been correctly developed in its design and in the hydraulic calculations. The basic purpose of the calculations is the selection of the diameters of the water pipes and the flow of water occurring, therein. This requires careful assessment of the results obtained and accuracy in the solutions applied. Issues, centred around the control of the results of the calculations, are difficult to present, algorithmically, as they are based mainly on the experience and knowledge of the designer. The authors of the present paper decided to use RBF artificial neural networks when calculating the water flow rate in particular sections of the aforementioned water pipes. In order to solve this problem, QK1 $\div$ QK7 deciding classes have been defined in order to describe problems related to the water flow rate in the pipework. The RBF neural network, based on the parameters of the water pipework, selects one of the QK1 QK7 classes; this allows the process of the evaluation of the results of the hydraulic calculations, thus obtained, to be automated, albeit only partially.
\end{abstract}

Keywords-water distribution system; RBF Neural Netowrks; the water flow rate; classification

\section{INTRODUCTION}

The water distribution system is a spatially large and complex system and comprises water pipes, their fittings and, in some cases, tanks and pumping stations. Its proper functioning is determined, not only by the appropriate selection of materials for its proper construction but also, by having been correctly developed, in its design and in the hydraulic calculations. The basic purpose of the calculations is the selection of the diameters of the water pipes, since this directly affects the flow of water occurring, therein. Designing a water distribution system, for a given topography, along with a site plan, as well as with specific water conditions, also requires the selection of optimal routes and a network structure that prevents water stagnation in the pipelines. This requires careful assessment of the results obtained and accuracy in the solutions applied. Issues, centred around the control of the results of the calculations, are difficult to present, algorithmically, as they are based mainly on the experience and knowledge of the designer. The authors of the present paper have decided to use RBF artificial neural networks, in their calculations of particular sections of the aforementioned water pipes, in assessing the water flow rate in pipework. In looped systems, a quite minor adjustment to the diameter of the loop, can radically change the water flow in the adjacent pipelines; evaluation of this parameter is, therefore especially important. The choice of the selection of one of the QK1 $\div$ QK7 classes, in order to describe problems related to the assessment of the water flow rate in pipework, has been defined. Numerical experiments were conducted to show how artificial RBF neural networks, can be used to assess the water flow rate in pipework, by selecting the appropriate $\mathrm{QK} 1 \div \mathrm{QK} 7$ class.

\section{ISSUES RELATING TO THE EVALUATION OF THE} Hydraulic CALCULATION RESUlts OF WATER Distribution SYSTEMS

The methodology for hydraulic calculations is well known and has been discussed, for many years, in other works $[1,2]$. Due to the high complexity of the computational algorithm, computer technology is used. An automatic evaluation of the results obtained may be applied to calculation programmes to a limited degree, only. The algorithm calculates the given data, however, the results obtained may be inadequate, from the point of view of the functional requirements of the water distribution system. Calculations are usually performed repeatedly while striving for a correct solution. One interesting problem seems to be the introduction of artificial intelligence techniques, in respect of data analysis; this would, at least partially, automate and improve the evaluation process of the calculation results obtained.

Artificial, neural networks are used, increasingly, in water supply issues. The article [3] provides a review of artificial intelligence methods, including artificial neural networks, in the design and operation of water distribution systems. The paper also [4] proposes recurrent neural networks for calculating the flow and looped systems in water supply networks. The use of multilayer perceptron, to calculate pressure losses in water pipes, is described in the article [5].

The method for the verification of results of hydraulic calculations, with the use of process diagnostics and artificial neural networks, is also presented in this paper [6]. The method for assessing pressure levels and the pattern of pressure zones, using artificial neural networks, is described in the article, at [7], while the solution to the above problem, with the use of the $C 4.5$ decision tree, is also discussed at [8]. The work [9] describes the proposal of an expert system and an artificial neural network, designed to assess pressure in the water supply network. Problems in the assessment of pressure loss, in which different methods of artificial intelligence were used, including expert systems, as well as the k-nearest neighbours method, are discussed in papers $[10,11,12]$. 


\section{Methodology For Assessing Flow RAtes IN WATER SUPPLY PIPES}

The problem, considered in the present article, is one of assessing the flow rate in individual sections of water supply pipes, which occurs in the calculation of water distribution systems. The diameter of the water pipe, as well as its location in the water distribution system, are taken into account in order to prevent water stagnation in the pipelines.

Naturally, it is possible to check the water flow rate or water flow speed immediately, in the results of calculations for individual sections. However, this method does not allow the actual reason for this condition to become any the clearer. A simple analysis of both the structure of the water supply network and the velocity of the water flow, allows the answer to the above question to be obtained and the appropriate remedial measures to be taken, in the event that incorrect values were used, at some earlier point. It has been assumed that a computer programme, for calculating water distribution systems, should be able to provide an intelligent analysis of calculation results and indicate the reason why a particular flow should be considered as incorrect. In connection with the above, QK1 $\div$ QK7 classes have been defined, in order to highlight cases in which there may be problems with the proper flow of water through pipework; one further class, corresponding to the correct conditions, has also been defined [10]:

- $\mathrm{QK} 1$ - correct flow through the water pipe

- $\mathrm{QK} 2$ - incorrect, that is, greatly reduced flow, due to the diameter of the duct being over-sized; correction of the diameter of the cable, located on the branching of the network, should not affect the flow of water in the adjacent sections

- $\quad$ QK3 - flow too rapid, caused by the incorrectly selected diameter of the water pipe; diameter too narrow, in relation to the flow; correction of the diameter of the cable, located on the branching of the network, should not affect the flow of water in the adjacent sections

- QK4 - location of the duct at the end of the water supply network, where small sections and water nodes diverge, in the case of the minimum diameter; it may be necessary, periodically, to rinse the duct in order to ensure adequate water exchange

- QK5 - flow on the section is small in relation to the diameter; the wire is located in the looped of the network, hence any correction to the diameter may cause a change of flow, in other sections

- QK6 - flow too high in relation to the diameter; cable is located in the network loop, hence any correction to the diameter may cause a change of flow, in other sections

- $\quad$ QK7 - cable located in a loop with the water flowing in from both sides; low water uptake results in a reduced flow

Using EPANET software [13], hydraulic calculations of exemplary water distribution systems were conducted and examples were developed, in order to generate a decision tree for the assessment of the water flow rate in the pipework. 4331 training examples, describing individual $\mathrm{QK} 1 \div \mathrm{QK} 7$ class, were prepared. Each example is described by the following arguments:

- the inner diameter of the pipework $\mathrm{D}_{\text {in }}$

- $\quad$ water flow rate through the cable $\mathrm{Q}_{\mathrm{n}}$

- water flow velocity $\mathrm{V}$

- an attribute STR, indicating whether the cable is located on the network branching or in the loop

- EP - an attribute denoting whether there is water outflow to the further sections "OUT", in the end node of the calculation section, or an inflow from another cable "IN", or possibly only water uptake from the final node "END", at the end of the network

A collection of training examples for three subsets: training, validating and testing. The selection of examples for particular subsets was made, using random sampling, with the assumption that the training set would account for $50 \%$ and the validating and testing sets would account for $25 \%$ of all training examples.

\section{NeURAl Networks With a RADIAL Basis FunCtion}

The radial network is a structure containing an input layer to which the signals are described by the input vector $\mathrm{X}=\left[\mathrm{x}_{1}, \mathrm{x}_{2}, \ldots\right.$, $\left.\mathrm{x}_{\mathrm{N}}\right]^{\mathrm{T}}$, a hidden layer with $\mathrm{K}$ radial neurons and an input layer. Neurons of the inner layer have radial activation functions, which are generally marked as $[14,15]$ :

$$
\varphi(\|X-C\|)
$$

where $\|\cdot\|$ is the distance of the input vector $\mathrm{X}$ from the centre of the radial $\mathrm{C}$ neuron in the $\mathrm{N}$-dimensional space. The most commonly used Euclidean measure is used to calculate the distance $r$.

The role of the neuron, hidden in the RBF networks, consists in the radial mapping of the space around the $C$ centre. The location of the neuron centre, in the N-dimensional space, is determined in the network learning process. The superposition of signals, coming from all $\mathrm{K}$ neurons, hidden in the RBF network, allows all network centres to be mapped thus,

$$
F(X)=\sum_{i=1}^{K} W_{i} \varphi\left(\left\|X-C_{i}\right\|\right)
$$

where $\mathrm{K}$ is the number of neurons in the hidden radial network.

The number of $\mathrm{K}$ neurons in the hidden layer and $\mathrm{C}$ centres should be determined in the process of the neural network training. The condition required for the RBF network to create an effective model for any function, however, is the provision of a sufficient number of radial neurons in the network structure. The number of radial neurons cannot be too large because it will not have the ability to generalise. The output value y of the radial neuron is determined on the basis of the distance $r$, by means of the radial function. The Gauss Function is used in RBF networks: 


$$
\varphi(r)=\exp \left(-\frac{r^{2}}{2 \sigma_{i}^{2}}\right)
$$

where $\sigma$ is the shape factor.

In the case of a multi-criteria classification, the number of neurons in the initial layer is equal to the number of classes; however, output should be understood as one variable with nominal values.

The training of radial networks consists of two stages:

- $\quad$ selection of centres and deviation from the centre, i.e. the smoothing coefficient

- $\quad$ selection of neuron weights in the output layer

The selection of $\mathrm{C}$ centres of the radial neurons was conducted using the K-means algorithm [16]. The size of the deviation, that is, the coefficient of smoothing, was determined by the k-nearest neighbours method.

The selection of weight values of the output neurons was made using the standard linear optimisation technique, which is a pseudo-inversion algorithm, that is, decomposition, according to singular values [14]. The quality of training of the output layer was evaluated using the sum-squares error function SOS, as described by the formula:

$$
E_{S O S}=\sum_{i=1}^{P}\left(y_{i}-t_{i}\right)^{2}
$$

where $\mathrm{P}$ is the number of training cases, $\mathrm{y}$ is the value at the output of the neural network and $t_{i}$ is the target value of the network for the i-th learning case.

\section{ApPlicAtion of RBF NeURAL NetWorks to Assess THE FLOW RATE IN WATER SUPPLY PIPES}

Based on a set of training examples containing an input data vector, $\mathrm{X}=\left[\mathrm{D}_{\text {in }}, \mathrm{Q}_{\mathrm{n}}, \mathrm{V}, \mathrm{STR}, \mathrm{EP}\right]^{\mathrm{T}}$ and one of the OK1 $\div \mathrm{QK} 7$ classes, appropriate for each training session on RBF artificial neural networks, was conducted. The evaluation of the neural network quality was conducted on the basis of the results of the validation set, using the Esos learning error. An additional parameter of the neural network assessment is the accuracy of classification $\eta$ defined as:

$$
\eta=\frac{\mathrm{n}_{\text {cor }}}{\mathrm{n}_{\text {all }}}
$$

where $\mathrm{n}_{\text {cor }}$ is the number of correctly classified training examples, $\mathrm{n}_{\text {all }}$ is the number of all training examples subjected to classification.

Detailed classification results for the training, validation and testing subsets are included in the confusion matrix. This is a square matrix in which information, regarding the individual classes that the examples actually belong to, is given in rows, while information, as to the classes into which they were classified, by the classifier, is given in columns. The diagonal contains examples that have been correctly categorised, while those located beyond the diagonal have been incorrectly classified. At the same time, examples beyond the diagonal, indicate the classes into which they were incorrectly classified.

Table 1 presents the training results of the RBF networks for assessing flows in water supply pipes. A neural network with 164 radial neurons, in the hidden layer, was adopted. The above neural network has the lowest number of $E_{S O S}$ training errors for the validation subset and a very high classification accuracy.

Figure 1 shows the diagram of the RBF network for the assessment of the water flow rate in the pipework, in which the activation of neurons in the initial layer is visible, indicating the choice of the class assigned to it.

In the table $1, \mathrm{~K}$ - number neurons of the inner layer, $\mathrm{E}_{\mathrm{SOS}}(\mathrm{L})$ - the error for the training subset, $E_{S O S}(V)$ - the error for the validation subset, $E_{S O S}(T)$ - the error for the test subset, $\eta(L)$ relevance of the classification for the training subset, $\eta(\mathrm{V})$ relevance of the classification for the validation subset, $\eta(T)$ relevance of the classification for the test subset.

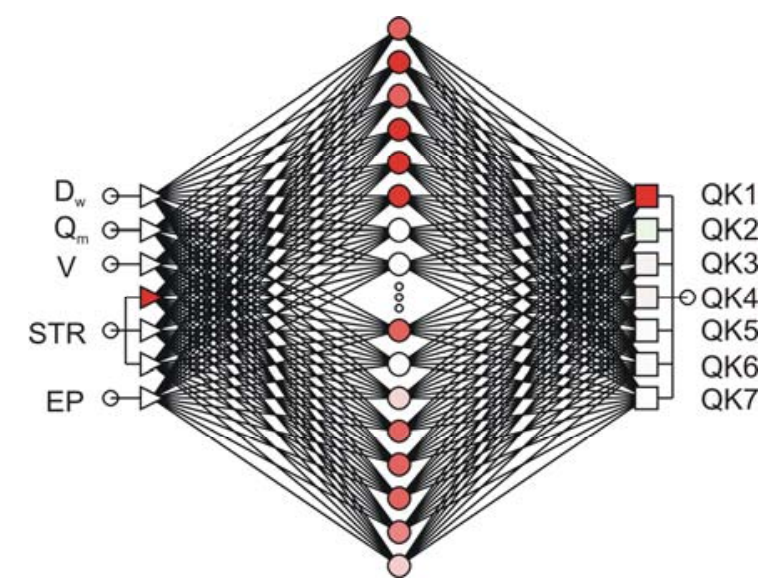

FIGURE I. A DIAGRAM OF THE RBF NEURAL NETWORK FOR THE ASSESSMENT OF THE WATER FLOW RATE

\section{SUMMARY AND CONCLUSIONS}

The motivation for research was the idea of creating additional modules for assessing the results obtained in the computer software, for the calculation of water distribution systems. Currently, this task is conducted by the software designer. In order to obtain the correct solution, calculations are conducted many times, hence intelligent solutions would certainly be very useful at the design stage. It seems that any assessment of the results obtained, indicative of computational problems, is an interesting direction for future research, in the field of the application of artificial intelligence methods. In this present paper, $\mathrm{QK} 1 \div \mathrm{QK} 7$ classes have been proposed, of which one, namely, QK1, describes the correct conditions, whereas the classes $\mathrm{OK} 2 \div \mathrm{QK} 7$ indicate various problems related to the water flow rate in the pipework. 
TABLE I. NEURAL NETWORKS FOR THE ASSESSMENT OF THE WATER FLOW RATE IN THE PIPEWORK

\begin{tabular}{|c|c|c|c|c|c|c|c|}
\hline No. & $\mathbf{K}$ & $\mathbf{E}_{\text {sos }}(\mathbf{L})$ & $\mathbf{E}_{\text {sos }}(\mathbf{V})$ & $\mathbf{E}_{\text {sos }}(\mathbf{T})$ & $\eta(\mathbf{L})$ & $\eta(\mathbf{V})$ & $\eta(\mathbf{T})$ \\
\hline 1 & 24 & 0.17854 & 0.18303 & 0.17187 & 0.89520 & 0.88920 & 0.90758 \\
\hline 2 & 62 & 0.11485 & 0.11599 & 0.11097 & 0.97230 & 0.98061 & 0.98059 \\
\hline 3 & 72 & 0.10599 & 0.11046 & 0.10365 & 0.97507 & 0.98153 & 0.98244 \\
\hline 4 & 88 & 0.09121 & 0.09996 & 0.09386 & 0.98892 & 0.98153 & 0.98891 \\
\hline 5 & 115 & 0.09302 & 0.10166 & 0.09675 & 0.98384 & 0.97599 & 0.98244 \\
\hline 6 & 142 & 0.08269 & 0.09205 & 0.08770 & 0.98892 & 0.98800 & 0.98429 \\
\hline 7 & 148 & 0.08061 & 0.09094 & 0.08659 & 0.98984 & 0.98984 & 0.98521 \\
\hline 8 & 164 & 0.07842 & 0.08831 & 0.08499 & 0.99123 & 0.98984 & 0.98614 \\
\hline
\end{tabular}

TABLE II. RESULTS OF THE CLASSIFICATION OF NETWORK NO. 8 FROM TABLE 1 FOR THE TEST SUBSET

\begin{tabular}{|c|c|c|c|c|c|c|c|}
\hline & QK4 & QK1 & QK3 & QK2 & QK5 & QK6 & QK7 \\
\hline QK4 & 166 & 0 & 0 & 0 & 0 & 0 & 0 \\
\hline QK1 & 0 & 136 & 1 & 1 & 2 & 4 & 0 \\
\hline QK3 & 0 & 1 & 133 & 0 & 0 & 0 & 0 \\
\hline QK2 & 0 & 1 & 0 & 241 & 0 & 0 & 0 \\
\hline QK5 & 0 & 1 & 0 & 0 & 148 & 0 & 0 \\
\hline QK6 & 0 & 2 & 0 & 0 & 0 & 129 & 0 \\
\hline QK7 & 0 & 0 & 0 & 0 & 0 & 0 & 116 \\
\hline
\end{tabular}

A set of 4331 training examples was prepared and experiments were conducted with RBF artificial neural networks, in order to find the right number of neurons in the hidden layer. An RBF network with 164 radial neurons was obtained. The above network, as used in the computer software programme for hydraulic calculations, will assign a class to each water pipe and will indicate whether the flow is correct or incorrect. This type of classification, additionally describes the problem occurring within a given section of the water pipe. The results obtained in the training of the RBF neural networks show that networks of this type demonstrate clearly defined classes very well and can be used in computer programmes.

\section{REFERENCES}

[1] R. K. Gupta, "Analysis and Control of Flows in Pressurized Hydraulic Networks", PhD, UNESCO-IHE Institute, Delft 2006.

[2] K. Lansey and L.W. Mays, "Hydraulics of water distribution systems", in: Water distribution systems handbook, L.W. Mays, Ed. New York: McGraw-Hill, 2000, pp.4.1-4.29.

[3] A. Czapczuk, J. Dawidowicz, and J. Piekarski, "Metody sztucznej inteligencji w projektowaniu i eksploatacji systemów zaopatrzenia w wodę", Annual Set of the Environment Protection, vol. 17, no. 2, 2015, pp. 1527-1544 (in Polish).

[4] C. Xu, F. Bouchart, and I.C. Goulter, "Neural networks for hydraulic analysis of water distribution systems, Innovation in Computer Methods for Civil and Structural Engineering", Cambridge: Civl-Comp Press, 1997, pp. 129-136.

[5] A. Czapczuk, J. Dawidowicz and J. Piekarski, “Application of Multilayer Perceptron for the Calculation of Pressure Losses in Water Supply Lines", Annual Set of the Environment Protection, vol. 19, 2017, pp. 200-210.

[6] J. Dawidowicz, "Diagnostyka procesu obliczeń systemu dystrybucji wody z zastosowaniem modelowania neuronowego", Rozprawy Naukowe no. 268, Białystok: Oficyna Wydawnicza Politechniki Bialostockiej, 2015 (in Polish).
[7] J. Dawidowicz, "Evaluation of a pressure head and pressure zones in water distribution systems by artificial neural networks", Neural Computing \& Application, 2017, doi:10.1007/s00521-017-2844-8.

[8] J. Dawidowicz, "System ekspertowy do oceny układu systemu dystrybucji wody sporządzony za pomocą wnioskowania indukcyjnego", Annual Set of the Environment Protection, vol. 14, pp.650-659, 2012.

[9] J. Dawidowicz, "Metody sztucznej inteligencji w diagnostyce wysokości ciśnienia $\mathrm{w}$ węzłach oraz układów sieci wodociągowych $\mathrm{w}$ procesie obliczeń hydraulicznych“, in Inteligentne systemy w inżynierii i ochronie środowiska, Poznan: PZiTS, 2007, pp.85-94 (in Polish).

[10] A. Czapczuk, "System ekspertowy do oceny przepływów i strat ciśnienia w układzie dystrybucji wody", PhD, Warszawa: Wydział Inżynierii Środowiska Politechnika Warszawska, 2013 (in Polish).

[11] A. Czapczuk and J. Dawidowicz, "Indukcja drzewa decyzyjnego do oceny strat ciśnienia na przewodach sieci wodociągowych", Gaz, Woda i Technika Sanitarna, vol. 89, no. 1, 2015, pp. 11-14 (in Polish).

[12] S. Biedugnis and A. Czapczuk, "The application of the 'K-nearest neighbour' method to evaluate pressure loss in water supply lines", Krakow: Technical Transactions, vol. 115, iss. 1, pp. 141-149, 2018, DOI: 10.4467/2353737XCT.18.011.7962.

[13] L .A. Rossman, "EPANET 2 User's manual“, EPA/600/R-00/057, National Risk Management Research Laboratory, Cincinnati: U.S. Environmental Protection Agency, OH, USA 2000.

[14] C. M. Bishop, "Neural networks for pattern recognition", Oxford: University Press, 1996.

[15] S. Haykin, "Neural networks: a comprehensive foundation", New Jersey: Prentice Hall Int., 1999.

[16] J. A. Hartigan and M. A. Wong, "Algorithm AS 136: K-Means Clustering Algorithm", Applied Statistics, vol. 28, 1979, pp. 100-108. 